Article

\title{
Enzymatic Esterification as Potential Strategy to Enhance the Sorbic Acid Behavior as Food and Beverage Preservative
}

\author{
Federico Zappaterra ${ }^{1}$, Daniela Summa ${ }^{2}{ }^{\oplus}$, Bruno Semeraro ${ }^{2}$, Raissa Buzzi ${ }^{1}$, Claudio Trapella $^{3}$, \\ Miguel Ladero ${ }^{4}(\mathbb{D})$, Stefania Costa ${ }^{1, *}$ (i) and Elena Tamburini ${ }^{1}$ (I) \\ 1 Department of Life Sciences and Biotechnology, University of Ferrara, Via L. Borsari, 46, 44121 Ferrara, Italy; \\ zppfrc@unife.it (F.Z.); raissa.buzzi@unife.it (R.B.); tme@unife.it (E.T.) \\ 2 GATE SRL, Via L. Borsari, 46, 44121 Ferrara, Italy; smmdnl@unife.it (D.S.); bsemeraro@gategreen.it (B.S.) \\ 3 Department of Chemistry and Pharmaceutical Sciences, University of Ferrara, Via Fossato di Mortara, 17, \\ 44121 Ferrara, Italy; trpcld@unife.it \\ 4 Department of Materials and Chemical Engineering, Chemical Sciences School, Complutense University of \\ Madrid, 28040 Madrid, Spain; mladerog@ucm.es \\ * Correspondence: cstsfn1@unife.it
}

Received: 28 August 2020; Accepted: 2 October 2020; Published: 3 October 2020

\begin{abstract}
Sorbic acid is the most commonly used preservative in the food industry. The antimicrobial inhibition of sorbic acid could be influenced by its lipophilic nature, which reduces its use in hydrophilic food formulations. Reactions between sorbic acid and glycerol catalyzed by lipases were studied in order to develop a novel sorbic acid derivate with a promising hydrophilic profile. The esterification reaction between sorbic acid and glycerol in a solvent-free system were performed with an immobilized lipase B from Candida antarctica (CALB). The glycerol sorbate product has been tested against $S$. griseus bacterium and Saccharomyces cerevisiae yeast. Results indicate that the esterification of sorbic acid with glycerol does improve its antimicrobial properties against Saccharomyces cerevisie. The reported results demonstrate that esterification can be used as a strategy to improve the antimicrobial activity of sorbic acid.
\end{abstract}

Keywords: sorbic acid; glycerol; esterification; lipase; CALB; antimicrobial

\section{Introduction}

Sorbic acid is a straight-chain alpha-beta-unsaturated fatty acid first isolated from the oil of unripe rowanberries in 1859 [1]. It acts as inhibitor of most molds, yeast, and some bacteria [2]. Sorbic acid, and especially its more soluble salts, known as sorbates, are used as preservative for food, animal feed, and cosmetic and pharmaceutical products [3]. The antimicrobial action of sorbates occurs at various stages of microbial life cycle (germination, outgrowth, and cell division) [4] and it may result in the alteration of the cell membrane, in the inhibition of transport systems and key enzymes, the creation of a proton flux into the cell, the inhibition of oxidative phosphorylation, or in a synergic effect of two or more of these factors $[5,6]$. The mode of action of sorbic acid on bacterial cells and spores has been reviewed by Sofos et al. [5], while York et al. reported the sorbic acid inhibition of the yeast Saccharomyces cerevisiae [6]. Sorbate acts as a competitive and reversible inhibitor of amino acid-induced germination [7], of several enzyme systems' activity (alcohol dehydrogenase, fumarase, anolase, aspartase, catalase, malate dehydrogenase, alfa-ketoglutarate dehydrogenase, succinic dehydrogenase, and ficin) [8], and of nutrient uptake [9]. The antifungal activity of sorbic acid seems to be related to an interference with the electrochemical membrane potential across the mitochondrial membranes [10]. Potassium sorbate is the most employed salified form of sorbic acid 
because of its higher solubility in water compared to sorbic acid (only $0.15 \mathrm{~g}$ per $100 \mathrm{~mL}$ vs. $58.5 \mathrm{~g}$ per $100 \mathrm{~mL}$ at room temperature) [5,11]. As is well known, solubility is one of the principal parameters that affects bioavailability [12]. The low solubility of sorbic acid in water can decrease its potential as a food preservative, influencing its bioavailability. Previous works suggested esterification as an strategy to create more active compounds $[12,13]$. Alcohols, especially ethanol, are reported to enhance sorbic acid solubilization [14]. However, in the development of a lipase-catalyzed esterification reaction, the choice of the appropriate organic solvent is crucial [15]. It is known that organic solvents might cause lipase inactivation [16]. For this reason, and due to its reactivity as an alcohol, ethanol cannot be chosen as the solvent for the esterification that is the subject of this study.

Esterification of lipophilic compounds with water-soluble molecules can increase the polarity and, thereby, improve the aqueous solubility of the resulting ester [15]. Furthermore, it is known that esters display good thermodynamic stability in vivo [17]. Traditionally, esterification reactions are identified as trans-esterification, in the presence of a base catalyst, and as esterification, in the presence of an acid catalyst [18]. Only since the 1990s is the biocatalyst activity of lipases (triacylglycerol hydrolases, EC 3.1.1.3) in esterification reactions calling attention, due to their significant activity and selectivity, properties that are maintained also in organic media, and mild operating conditions, thus favoring their application in the fine chemicals industry, in particular in the presence of thermosensitive products [19]. Several publications show enzymatic esterification strategies to improve the water solubility of lipophilic compounds. Jahangiri et al. [15] report a lipase-catalyzed reaction between the water insoluble bixin and sorbitol in order to obtain a novel bixin derivative with a hydrophilic profile. Furthermore, several studies have demonstrated antimicrobial activity improvements after esterification of aromatic compounds [20-22].

Until today, enzymatic catalysis in organic media has been widely studied, but this process suffers from several problems regarding the industrial scale-up. First, it requires a large amount of expensive and toxic solvents, which should be avoided considering the process affordability/cheapness (high product recovery and low energy costs). Novel solutions include hydrofluorocarbons, supercritical fluids, and ionic liquids that may be relevant in the choice of solvents [22], in particular if the final target of the product is the food industry. In this field, dry media reactions offer an economic and environmentally friendly option, avoiding the use of solvents. For this reason, we esterified sorbic acid with glycerol to obtain a chemical compound with potentially increased antimicrobial activity as result of better solubility and consequent better bioavailability. Furthermore, potassium sorbate, a very popular food and drink preservative, shows a much higher solubility than sorbic acid, but has some negative aspects. In fact, due to its $\mathrm{pKa}$, when the $\mathrm{pH}$ is up to 5, potassium sorbate is charged and relatively impermeable to the membrane. Thus, to achieve the desired antimicrobial activity, the concentration of potassium sorbate often needs to be increased above the maximum regulatory levels allowed in foods and drinks. For this reason, an ester between sorbic acid and glycerol could be a valuable solution to the membrane permeability issue of potassium sorbate.

Effective esterification of eugenol in solventless systems has been reported, with augmented antimicrobial activity against several bacteria compared to pure eugenol [23]. Encouraging results were also obtained considering the antifungal activity of the eugenol isobutyryl and acetyl esters that inhibit dermatophytes M. gypseum and T. mentagrophytes growth [24]. The scientific literature reports several works where $C$. antarctica lipase B performed efficiently as a biocatalyst of esterification reactions [25]. CALB enzyme is the most widely used for solventless esterification reactions because its tiny lid closes only partially the active site of the enzyme [26], making interfacial activation unnecessary. This enzyme has previously proved to be a good choice to work in systems without solvent-water interface [19]. For these reasons, CALB seems to be a good choice for monophasic esterification reactions [27]. This enzyme is present on the market in both its free and immobilized forms [28]. The immobilized form of CALB can improve its stability and catalytic activity even in organic solvents [29]. CALB immobilized form is among the most stable commercialized enzymes, facilitating its industrial applications [30]. Starting from different types of acids, glycerides syntheses have been 
reported, leading to its application in several industrial sectors, in particular using chemical and enzymatic catalysts in the pharmaceutical and food industries. Ravelo et al. [10] and Tamayo et al. [12] have shown a successful strategy to perform esterification reactions catalyzed by lipase between benzoic acid or ibuprofen and glycerol in a solventless system [14]. Therefore, we aimed to exploit a solventless media strategy to perform the lipase-catalyzed esterification of sorbic acid with glycerol. The liquid nature of this short sugar alcohol allowed us to remove any organic solvent from our enzymatic synthesis strategy. Indeed, in this reaction, glycerol acts both as reagent and as a solvent.

Glycerol (propane-1,2,3-triol) is a polyol characterized by the presence of three hydroxylic groups, which confer to the compound the following properties: high hygroscopicity, high boiling point, and low vapor pressure. This nontoxic viscous liquid is widely used in chemical, cosmetic, pharmaceutical, and food industries [17]. Recently, glycerol availability grew simultaneously with the large increase in biodiesel production according to the international environmental laws (IEL). Glycerol is indeed a major byproduct of the biodiesel manufacturing process, representing approximately $10 \% w / w$ of biodiesel. Its consequent higher affordability allowed novel uses, different from the traditional direct ones applied in the food, cosmetic, and pharmaceutical fields. Thus, the use of glycerol as raw material paves the way for the strengthening of sustainable synthesis processes. [31]. The ability of glycerol and other polyhydric alcohols to confer stability to proteins is a widely recognized phenomenon [32]. Polyols, like glycerol, are frequently used as cosolvent for protein stabilization [33]. Glycerol is known to shift the native protein structure to more compact states [34], prevent the loss of enzymatic activity, increase the thermal unfolding temperature, and inhibit irreversible aggregation of proteins [35]. Moreover, glycerol has been reported as a nontoxic, biodegradable, and recyclable green solvent for high product yields and selectivity in catalysis and enzymatic catalysis [36,37].

In this paper, a monophasic solvent-free esterification of sorbic acid with glycerol has been carried out using a commercial immobilized enzyme Candida antarctica lipase type B (Figure 1), in order to improve water solubility of the resulting ester and test its antimicrobial activity in comparison with sorbic acid. In particular, glycerol can act as a hydrophilic moiety when combined with sorbic acid, with the concomitant effect of increasing polarity and, consequently, water solubility. To the best of the authors' knowledge, this is the first attempt concerning the enzymatic esterification of the sorbic acid with glycerol in a solventless system. A comparison in terms of antimicrobial activity of pure sorbic acid and its glycerol-ester against the yeast Saccharomyces cerevisiae and the bacteria Streptomyces griseus is also provided in this work. This yeast was previously reported as model in microbial stability of ready-to-drink beverages studies [6]. 
(a)<smiles>CC=CC=CC(=O)O</smiles>

(b)<smiles>OCC(O)CO</smiles>

(c)<smiles>CC=CC=CC(=O)OCC(O)CO</smiles>

Figure 1. Between sorbic acid and glycerol catalyzed by immobilized lipase B from C. antarctica. (a) sorbic acid, (b) glycerol, (c) glycerol ester of sorbic acid.

\section{Materials and Methods}

\subsection{Enzyme and Chemicals}

CALB (lipase B from C. antarctica immobilized on acrylic resin immobead 150, recombinant from Aspergillus oryzae; $\geq 1800 \mathrm{U} / \mathrm{g}$ ) was purchased from Sigma-Aldrich [25]. Sorbic acid ( $\geq 99 \%$ pure) was purchased from Fluka, Germany. Potassium Sorbate ( $\geq 99.0 \%$ pure) was purchased from Sigma-Aldrich. Pure glycerol was obtained from Sigma-Aldrich. Methanol-d4 degree $99.8 \%$ was purchased from Sigma-Aldrich. All other solvents were of ACS grade. Silica gel (60 A, 70-230 mesh, 63-200 $\mu \mathrm{m})$ was obtained from Sigma-Aldrich. Nuclear magnetic resonance (NMR) spectra of these compounds were recorded with a 400- MHz Varian Gemini spectrometer; Varian, Palo Alto, CA, USA). IR spectra was recorded by Perkin Elmer FTIR Spectrum 100 infrared spectrometer equipped with ATR using a ZnSe Diamond.

\subsection{Synthesis of Glycerol Ester of Sorbic Acid}

Sorbic Acid (100 mg), pure glycerol $(10 \mathrm{~mL})$, and $40 \mathrm{mg}$ of immobilized CALB were placed inside a $20 \mathrm{~mL}$ capped vial. The reaction solution was mixed using a magnetic stirrer hot plate at $55^{\circ} \mathrm{C}$ and $720 \mathrm{rpm}$. The use of a crosshead magnetic stirrer was employed to avoid enzyme support disruption. At the end of $24 \mathrm{~h}$ of reaction, samples were stocked at $-20^{\circ} \mathrm{C}$, aiming to inhibit the enzymatic activity. A negative control of the reaction was prepared without the use of lipase. Ravelo et al. reported kinetic analysis about the solvent-free synthesis of ibuprofen monoglyceride exploiting an immobilized form of CALB [38]. In order to determine the amount of the enzyme, a range between 1 and $5 \mathrm{~g} / \mathrm{L}$ has been tested. Samples were withdrawn for every concentration and analyzed by JASCO HPLC modular system equipped with reverse phase column (Synergi $4 \mu \mathrm{m}$ Hydro-RP $80 \AA-250 \times 4.6 \mathrm{~mm}$ ), refractive index (model RI-4030) and UV/vis detector (model UV-4070); $30{ }^{\circ} \mathrm{C}$, mobile phase 90:10 $\mathrm{MeOH} / \mathrm{H}_{2} \mathrm{O}$ ( $\mathrm{pH}$ 2.2), $0.8 \mathrm{~mL} / \mathrm{min}$. The conversion yield has been calculated using the following equation:

$$
X=\frac{A_{M G}}{A_{S}-A_{M G}}
$$


where $A_{M G}$ means area monoglyceride, and $A_{S}$ means area of sorbic acid.

\subsection{Thin Layer Chromatography (TLC)}

Thin layer chromatography was performed to monitor the reaction process. $100 \mu \mathrm{L}$ of the reaction mixtures were diluted in $8 \mathrm{~mL}$ of acetone and $1.9 \mathrm{~mL}$ of distilled water. This step was performed because of the glycerol high viscosity, which made difficult its sowing on TLC plate. The standard sorbic acid sample has been suspended in methanol $\left(1 \mathrm{mg} / \mathrm{mL}^{-1}\right)$. TLC (Silica gel 60, $5 \times 10 \mathrm{~cm}$, Merck, Germany) plates were analyzed with the elution system ethyl acetate/hexane/acetic acid 60:35:5 $(v / v / v)$. Starting from the conditioning of the TLC chamber, the mobile phase has been prepared in $10 \mathrm{~mL}$ final volume with this proportion: $6.5 \mathrm{~mL}$ ethyl acetate, $3.5 \mathrm{~mL}$ hexane, and $0.5 \mathrm{~mL}$ acetic acid. The compound Rf of sorbic acid was 0.72 , while glycerol, more hydrophilic, showed a retention factor (Rf) of 0.23 . In these conditions, the Rf of the glycerol ester of sorbic acid was 0.34 . This $\mathrm{Rf}$ characterizes a molecule with a higher affinity for the stationary phase of TLC compared to the sorbic acid. Indeed, the presence of two hydroxyl groups in the ester of sorbic acid decreases its $\log \mathrm{P}$, and, consequently, raises its hydrophilicity and water solubility.

\subsection{Purification and Spectroscopic Characterization of Glycerol Ester of Sorbic Acid}

Before proceeding with the purification, the entire volume of initial sample was washed three times with $10 \mathrm{~mL}$ ethyl acetate, in order to remove the excess of unreacted glycerol and extract the ester into the organic solvent. Once the ethyl acetate has been removed with a rotary evaporator, the separation of the glycerol ester was achieved by glass column chromatography. Silica gel column was prepared with the following eluent solution: acetate/hexane/acetic acid 60:35:5 (v/v/v). The eluted fractions were collected, the solvent was removed using a rotatory evaporator, and the rest was analyzed by NMR and uHPLC. The glass column chromatography allowed for obtaining $101 \mathrm{mg}$ of the product of interest, with a conversion yield of $61 \%$. The purified molecule obtained was analyzed by IR and NMR (provided as Supplementary Materials). IR: 3394.89; 2933.42; 1703.14; 1643.86; 1243.02; $1141.21 ; 997.14 \mathrm{~cm}^{-1}$.

The NMR (acquired with a 400-MHz Varian Gemini spectrometer; Varian, Palo Alto, CA, USA) sample was prepared by dissolving it in deuterated methanol $(1 \mathrm{~mL}) .{ }^{1} \mathrm{H}$ - and ${ }^{13} \mathrm{C}-\mathrm{NMR}$ spectra showed that the compound structure was the expected one. Because of the previous purification of the ester, the presence of adequate signals of glycerol $(\delta=4.1-4.4 \mathrm{ppm})$ and sorbic acid $(\delta=1.85 \mathrm{ppm})$ indicates a successful esterification. NMR Spectra showed the following peaks; ${ }^{1} \mathrm{H}$ NMR $(400 \mathrm{MHz}$, Methanol-d4) $\delta 7.30(\mathrm{dd}, J=15.3,10.1 \mathrm{~Hz}, 1 \mathrm{H}), 6.32-6.14(\mathrm{~m}, 2 \mathrm{H}), 5.84(\mathrm{~d}, J=15.3 \mathrm{~Hz}, 1 \mathrm{H}), 4.21(\mathrm{dd}$, $J=11.5,4.4 \mathrm{~Hz}, 1 \mathrm{H}), 4.12(\mathrm{dd}, J=11.4,6.3 \mathrm{~Hz}, 1 \mathrm{H}), 3.91-3.80(\mathrm{~m}, 1 \mathrm{H}), 3.57(\mathrm{dd}, J=5.6,2.0 \mathrm{~Hz}, 2 \mathrm{H})$, $1.86(\mathrm{~d}, J=5.9 \mathrm{~Hz}, 3 \mathrm{H}) \cdot ;{ }^{13} \mathrm{C}$ NMR $(101 \mathrm{MHz}$, cd3od) $\delta 168.93,147.00,141.05,130.97,119.46,71.22,66.52$, $64.06,18.70$.

\subsection{Analytical uHPLC-MS Method}

uHPLC-MS identification was carried out using an Waters Acquity UPLC equipped with a ZQ 2000 ESI mass spectrometry (Waters, Milford, MA, USA) and Mass Link software (Waters, Milford, MA, USA). The $2.6 \mu \mathrm{m}$ Kinetex $50 \times 4.6 \mathrm{~mm}$ C18 column was chosen to perform the analysis. The mobile phases used were water with $0.1 \%$ formic acid as solvent $\mathrm{A}$ and acetonitrile with $0.1 \%$ formic acid as solvent $\mathrm{B}$. The liquid chromatography ran in a gradient condition from $100 \% \mathrm{H}_{2} \mathrm{O}$ at $\mathrm{t}_{0}$ to $100 \%$ acetonitrile at $\mathrm{t}_{5}$ (5 min) under a flow rate of $0.3 \mathrm{~mL} / \mathrm{min}$. The column operated at a stationary temperature of $40^{\circ} \mathrm{C}$. Temperature, nebulizer pressure, and flow rate of drying gas $\left(\mathrm{N}_{2}\right)$ were, respectively, $230^{\circ} \mathrm{C}, 35 \mathrm{psi}$ and $10 \mathrm{~L} / \mathrm{min}$. The further operation parameters were $1200 \mathrm{~V}$ for nozzle voltage and $2500 \mathrm{~V}$ for the capillary voltage. Mass spectra were tracked in a mass-to-charge $(\mathrm{m} / \mathrm{z})$ ratio range of $150-500$ in positive ion detection mode. 


\subsection{Evaluation of Antibacterial and Antifungal Activity}

The antibacterial and antifungal activity of the glycerol ester of sorbic acid was assessed by disc diffusion and minimum inhibitory concentration methods. The disk diffusion (DD) technique allows the identification of several microorganisms' sensibilities against pharmaceutical compounds, and it is adequate when the resistance mechanism occurs owing to the antimicrobial agent destruction by the microorganism [39]. The bacterial species was Streptomyces griseus while the choice of the fungal species fell on Saccharomyces cerevisiae. The cultures were maintained in the laboratory as agar slants on a suitable culture medium: i.e., GYM (Glucose-Yeast extract-Malt extract) for Streptomyces griseus, and YMB (Yeast Mannitol Broth) for the yeast. In order to evaluate biological activity, mother cultures of each microorganism were set up in Petri dishes and grown until confluence. Then, appropriate agar medium (GYM or YMB) and different quantities of the tested compounds were added in other Petri dishes. The final concentrations reached are shown in Table 1.

Table 1. Drug concentrations tested against S. cerevisiae and S. griseus.

\begin{tabular}{lcccccc}
\hline \multicolumn{7}{c}{ Tested Drugs Concentrations $\left(\mathbf{m g} / \mathbf{m L}^{-\mathbf{1}}\right)$} \\
\hline S. cerevisiae & 0.05 & 0.075 & 0.100 & 0.125 & 0.150 & 0.175 \\
S. griseus & 0.15 & 0.25 & 0.50 & 0.75 & 1.00 & 1.25 \\
\hline
\end{tabular}

Three replicates were used for each concentration. $100 \mu \mathrm{L}$ of the suspension containing $10^{6}$ colony-forming units (CFU)/mL of microbial cells were spread on Petri dishes with appropriate agar-based growth medium (GYM or YMB). The compounds were solubilized using a 50\% ethanol solution. A negative control was prepared by adding equal quantities of this solution. The agar surface was first inoculated with the specific test microorganism. Then, filter paper disks of $5 \mathrm{~mm}$ diameter were slightly soaked using $10 \mu \mathrm{L}$ of drug derivative solution and placed on the agar surface. Clotrimazole [1 mg/mL] and chloramphenicol $[2 \mathrm{mg} / \mathrm{mL}]$ were added at the positive controls, while the disks with solvent were made as negative controls. Cultured plates were kept in an inverted position during incubation at $28{ }^{\circ} \mathrm{C}$ for 6 days. The areas where the growth microorganism was stopped by the antibacterial agents are called inhibition zones. In order to determine the antibacterial activity, the diameters of the inhibition zones for the test organism were measured in millimeters (mm), including disk diameter of $5 \mathrm{~mm}$, and compared to the negative controls. To measure the diameter of the inhibition zone, the software ImageJ has been employed as image analyzer. Digital images of the Petri dishes were analyzed after calibrating the software. The calibration step correlates pixels of a reference in the image with the real word distance measurement $(\mathrm{mm})$. Inhibition zones were selected, and the diameter of the selection were displayed in the "results" window of the software.

Moreover, minimum inhibitory concentration (MICs) evaluations were performed. MIC were commonly defined as the lowest concentration of compound that completely inhibited $\left(\mathrm{MIC}_{100}\right)$ or reduced to $50 \%\left(\mathrm{MIC}_{50}\right)$ clearly visible the microbial growth after the whole period of incubation, which was 6 days. These studies of the newly formed glycerol esters of sorbic acid will be improved with tests of aqueous solubility and stability at different $\mathrm{pH}$ values.

\section{Results and Discussion}

\subsection{Sorbic Acid Monoglyceride Production}

In this work, we aimed to employ a monophasic system to reach an effective esterification reaction between sorbic acid and glycerol in order to develop a novel sorbic acid derivate with a promising hydrophilic profile. Glycerol has proved to be a good candidate for the solubilization of sorbic acid in our experimental conditions. The viscosity of glycerol, together with the choice of a crosshead magnetic stirrer and the right stirring speed, allowed the enzyme to remain highly stable and perfectly separable from the medium. Glycerol viscosity and the selection of the right magnetic stirrer permit minimizing 
the contact surface between the reactor wall and the stirrer, thus avoiding particle degradation and, in consequence, ensuring the physical integrity of the enzyme support.

The effect of enzyme concentration on the conversion of sorbic acid has been evaluated through reverse-phase HPLC and allowed us to set up the enzyme concentration to $4 \mathrm{~g} \mathrm{~L}^{-1}$. As shown in Figure 2, the conversion yield increased with the amount of enzyme following a hyperbolic trend typic in the esterification reactions lipase catalyzed. At higher enzyme concentrations, more active sites are present for substrate binding. Therefore, the reaction rate increases. No improvement is observed after $4 \mathrm{~g} \mathrm{~L}^{-1}$, so these values were selected as the most adequate enzyme concentration.

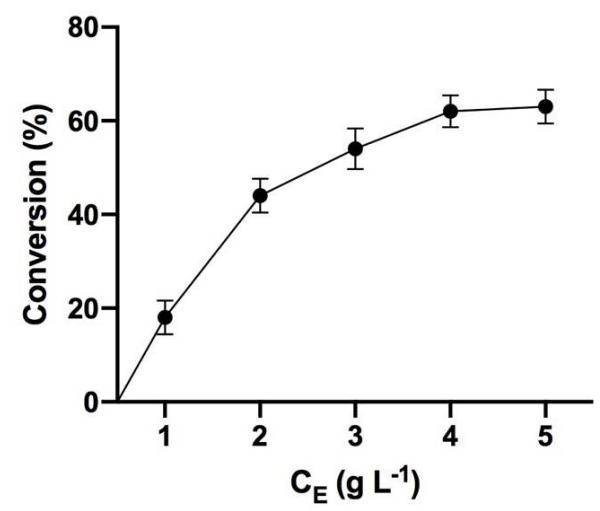

Figure 2. Effect of enzyme concentration at 720 RPM conversion yield of sorbic acid.

It has been previously observed that migration of compounds such as glycerol, 2-hydroxyethyl benzoate, 2-hydroxyethyl sorbate, and sorbic acid occurs from immobilized forms of CALB, as they are used as stabilizers [40]. In this work, due to the minute concentration in which these compounds are present in CALB and, in some cases (glycerol, sorbic acid), the presence of much higher concentrations of such compounds in the reaction liquid, their effect on the reaction can be considered negligible. In any case, the chromatographic analysis here performed did not report the presence of most of these compounds, despite the fact that they have a very similar LogP to that of the compounds here studied.

Water activity has been previously reported in literature for this kind of glycerol esterification [41]. In fact, a small amount of water (about $10 \% v / v$ ) can be an important strategic advantage. Indeed, water can enhance mass transfer by reducing the viscosity of glycerol [38] and enhance the biocatalyst flexibility, resulting in better esterification activity [38,42].

After IR and NMR, further proof of the effective lipase-catalyzed esterification has been obtained by uHPLC-MS analysis. The result from the reverse phase separation showed that glycerol sorbate eluted at $0.94 \mathrm{~min}$ (Figure 3; peak No 1). Because of the reaction conditions $\left(55^{\circ} \mathrm{C}, 24 \mathrm{~h}\right)$, no 2-monoacylglycerol (2-MAG) regioisomer as by-product seems to have formed. This interesting aspect remains to be investigated and will be the subject of further studies. Curiously, no 1,3-diester was found. Indeed, this compound would be more lipophilic than the sorbic acid monoglyceride and would be held back by the 18 column, producing a peak at retention times higher than the monoglyceride. 


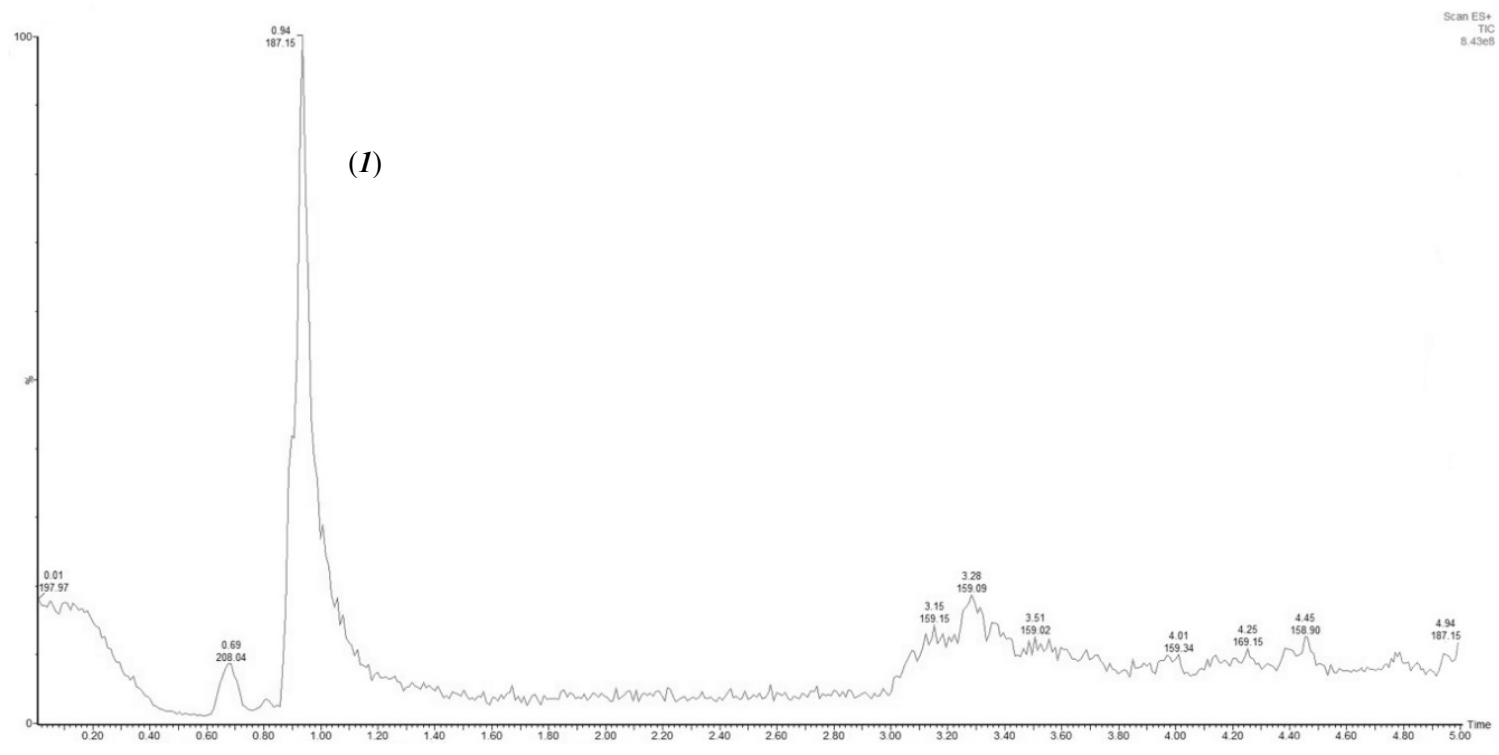

(a)

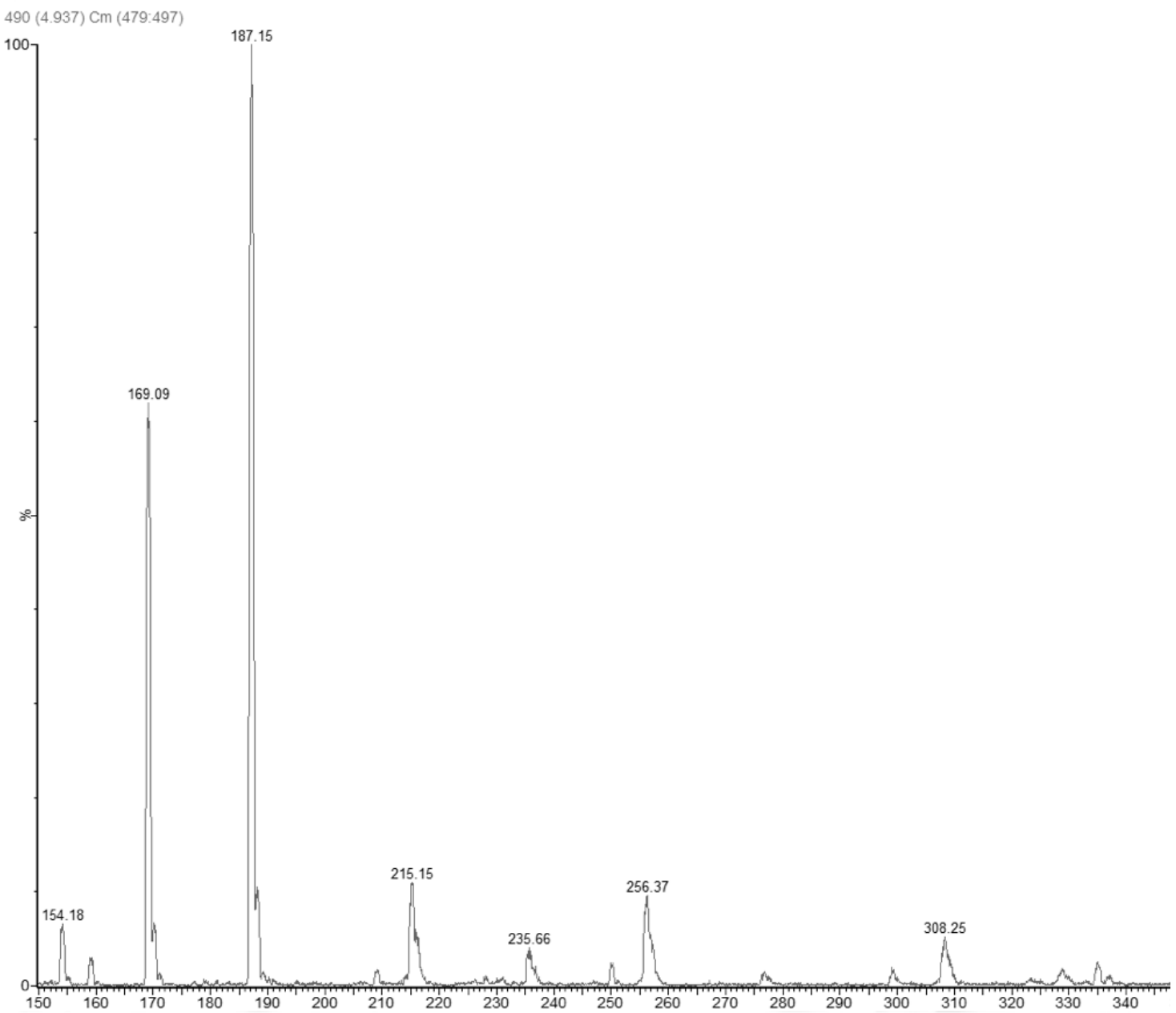

(b)

Figure 3. uHPLC/MS analyses of lipase-catalyzed esterification of sorbic acid and glycerol by immobilized CALB in solventless media; (a) uHPLC chromatogram, showing the peak of glycerol sorbate (peak No 1) at $0.94 \mathrm{~min}$; (b) ESI+/MS spectrum of the peak No 1, showing the ester product by electro spray ionization mass spectroscopy. 
Electrospray ionization (ESI) was performed on the peaks of the HPLC product separations to obtain mass spectra. The results from the mass spectrometry confirmed that the expected esterification reaction occurs between the carboxylic acid group and oxydril group of glycerol. The newly formed product mass prediction was $m / z$ 186. The fragmentation pattern showed most high peaks at $m / z$ 187 (peak No 2) and 169 (peak No 3), identifying the glycerol sorbate. Peaks appearing at an $\mathrm{m} / \mathrm{z}$ ratio of 187 and 169 represent the ionized $[\mathrm{M}+\mathrm{H}]^{+}$and $[\mathrm{M}-\mathrm{OH}]^{-}$. To the best of our knowledge, this enzymatic esterification of sorbic acid with glycerol is reported for the first time. Until now, CALB lipase has been proposed as biocatalysts for a similar esterification reaction between benzoic acid and glycerol [19]. This strategy was demonstrated to be an successful way to minimize the effect of water in the esterification/hydrolysis activity equilibrium of the lipase. In fact, a reaction environment completely made of glycerol creates a huge disequilibrium of stoichiometry ratio between alcohol (134 mmoles) and acid ( 0.89 mmoles) that boosts the esterification reaction, avoids the hydrolysis due to the small amount of water produced $(0.89$ mmoles at complete sorbic acid conversion into the sorbate), and favors the production of the monoglyceride of the acid, avoiding the formation of di- and triglycerides. Thus, the excess of glycerol is one of the advantages of this esterification approach. This polyol excess shifts the equilibrium of formation of the ester bond towards ester and water products. Moreover, the excess glycerol could easily be recovered and used again as solvent and reagent in batch processing or recycled in a continuous process.

\subsection{Antimicrobial Activity}

Two models were chosen to test the antimicrobial activity of the ester; the bacterium Streptomyces griseus, and the yeast Saccharomyces cerevisiae. Disc diffusion (DD) and minimal inhibitory concentration assays (MIC) were performed. Cultures of a bacterium (S. griseus) and a yeast (S. cerevisiae), with a cell density of $7 \times 10^{6} \mathrm{CFU} / \mathrm{mL}$, were exposed to different concentrations of the preservative and its ester (Table 1).

The disc diameters of the inhibition zone are shown in Table 2. The antimicrobial activity of the ester was compared to sorbic acid, the currently used antimicrobial agents often used as preservatives in food object of this research. The antimicrobial activity of potassium sorbate, the potassium salt of sorbic acid, was also assessed because of its enhanced solubility compared to sorbic acid. This parameter is the one that identifies potassium sorbate as the current choice of microbial control in foods.

Table 2. Antimicrobial activity of sorbic acid, glycerol and the two positive controls chloramphenicol and clotrimazole.

\begin{tabular}{cc}
\hline Streptomyces griseus & DD \\
\hline Chloramphenicol & $18 \mathrm{~mm} \pm 0.3$ \\
Sorbic acid & $/$ \\
Glycerol sorbate & $/$ \\
Potassium sorbate & \\
\hline Saccharomyces cerevisiae & $18 \mathrm{~mm} \pm 0.2$ \\
Clotrimazole & $10 \mathrm{~mm} \pm 0.4$ \\
Sorbic acid & $11.5 \mathrm{~mm} \pm 0.1$ \\
Glycerol sorbate & $12.6 \pm 0.2$ \\
Potassium sorbate &
\end{tabular}

The antifungal effect of sorbic acid, as well as glycerol sorbate, against $S$. cerevisiae was clearly confirmed by the disk diffusion experiments. The diameters of the inhibition zone of the newly synthesized glycerol ester of sorbic acid were $11.5 \mathrm{~mm}$ for $S$. cerevisiae, while sorbic acid caused an inhibition zone of $10 \mathrm{~mm}$. YMB was $\mathrm{pH}$ 6.5. Due to its $\mathrm{pKa}$ (4.76), potassium sorbate was partially charged. However, its antimicrobial activity was better than the sorbic acid ester. For this reason, no tests at different $\mathrm{pH}$ ranges have been conducted. The yeast growth inhibition of the ester was higher than the not esterified sorbic acid. Therefore, esterification could be an interesting strategy 
to increase antimicrobial activity of food preservatives. This strategy will be further investigated by designing other esters with increased water solubility and, consequently, antimicrobial activity. According to the results presented in Table 2, it can be noted that glycerol sorbate as well as sorbic acid showed a good inhibitory effect against the yeast specie tested but not for the bacterium. However, we found that glycerol sorbate, as well as sorbic acid, does not inhibit growth of the Gram-positive bacterium $S$. griseus. This is probably due to the more complex cell wall structure of Gram-positive bacteria, which has additional lipopolysaccharides on the outer surface that generally reduces the ability of most antibiotics and extracts to penetrate the bacterial cells [43]. Furthermore, it has been reported how some microorganisms, for example Acetobacter species, are able to degrade sorbic acid using it as carbon source [2].

The MIC values of glycerol sorbate on S. cerevisiae were on the range of $0.14 \mathrm{mg} / \mathrm{mL}$ (Table 3). Natural products presenting MICs of $\leq 1.00 \mathrm{mg} / \mathrm{mL}^{-1}$ are normally considerate noteworthy in terms of antimicrobial activity [44]. With this assumption, although potassium sorbate is the compound with the lowest MIC, the antimicrobial activity of the sorbic acid ester in this work results to be good for the control of the yeast $S$. cerevisiae. Moreover, the growth inhibition of the glycerol ester of sorbic acid resulted to be better compared to the not-esterified food preservative sorbic acid.

Table 3. Susceptibility of S. cerevisiae to sorbic acid and glycerol sorbate.

\begin{tabular}{ccc}
\hline & \multicolumn{2}{c}{ S. Ccerevisiae } \\
\hline MIC $_{\mathbf{5 0}} \mathbf{~}^{\mathbf{1}}$ & $\mathbf{M I C}_{\mathbf{1 0 0}}$ \\
\hline Sorbic acid & $0.097 \pm 0.0016$ & $0.150 \pm 0.001$ \\
Glycerol sorbate & $0.090 \pm 0.001$ & $0.140 \pm 0.0008$ \\
Potassium Sorbate & $0.080 \pm 0.001$ & $0.125 \pm 0.003$ \\
\hline
\end{tabular}

${ }^{1}$ MIC: Minimum Inhibitory Concentration $\left(\mathrm{mg} / \mathrm{mL}^{-1}\right)$, described as the lowest concentration of the compound that totally inhibited (MIC 100 ) or reduced growth to $50 \%\left(\mathrm{MIC}_{50}\right)$.

Nevertheless, additional safety information regarding this ester is required to obtain approval as food, beverage, or cosmetic preservative. As widely discussed in the literature, health information will need to investigate the effects of these additives and the consequences of their long-term dietary consumption. Indeed, though the actuals salts benzoate and sorbate are widely used compounds for food and beverage preservation, there continues to be a concern about their complete safety. Cell culture studies and model organisms have shown some issues. Benzoate and sorbate are reported to results in chromosome aberrations in cultured human lymphocytes. Thus, exposure to these agents should be evaluated in terms of downsizing [45]. About this, the positive aspects reported in the literature regarding the use of monoglycerides as preservatives in food and drinks can be of great interest. Monoacylglycerols, like monocaprin and monolaurin, used as fruit juice preservatives, suppressed or prevented the growth of filamentous fungi in vitro [46]. Monoglycerides also inhibited the germination of bacteria like Bacillus cereus and Clostridium botulinum [47]. Model membrane-based biophysical measurement techniques showed that fatty acid and monoglycerides as antimicrobial destabilize phospholipid membranes, causing several direct and indirect inhibitory effects [48]. Therefore, the importance of developing monoglycerides-based preservatives, as well as deeply testing their effects on human safety, turns out to be very essential.

\section{Conclusions}

The employment of sorbic acid as a preservative in foods consisting of water is limited by its hydrophobic nature. In the present study, solventless lipase-catalyzed esterification of sorbic acid and glycerol was performed to obtain glycerol sorbate. The immobilized form of C. antarctica lipase B has proven to be a suitable catalyst to efficiently esterify glycerol and sorbic acid in reaction environment with water close to zero. To the best of our knowledge, 2,3-dihydroxypropyl-sorbate (glycerol sorbate) has been characterized $\left({ }^{1} \mathrm{H}-,{ }^{13} \mathrm{C}-\mathrm{NMR}\right.$ and IR) for the first time. MS spectroscopy assays confirmed 
the effective esterification of sorbic acid. Lately, the antimicrobial activity of glycerol sorbate against S. griseus and S. cerevisiae has been evaluated, giving encouraging results for the control of the fungal model. With this study, we aimed to provide a scalable way to design synthesis production processes of bioactive compounds.

Supplementary Materials: The following are available online at http://www.mdpi.com/2311-5637/6/4/96/s1, Figure S1: ${ }^{1} \mathrm{H}-\mathrm{NMR}$ spectra of glycerol sorbate, Figure S2: ${ }^{13} \mathrm{C}-\mathrm{NMR}$ of glycerol sorbate; Figure S3: IR spectra of glycerol sorbate.

Author Contributions: Conceptualization and writing_-original draft, F.Z., investigation and analysis F.Z., D.S., B.S., R.B., supervision and project administration S.C., E.T., methodology, C.T., Writing—review and editing M.L. All authors have read and agreed to the published version of the manuscript.

Funding: This research was funded by Ambrosialab, Ferrara, Italy (Grant 2019). Italian Ministry of Education University and Research (Grant MIUR-PRIN 2017E84AA4_002).

Acknowledgments: The authors would like to acknowledge Luca Vergnani, Elisa Durini and Elena Cesa for technical assistance.

Conflicts of Interest: The authors declare no conflict of interest. The funders had no role in the design of the study; in the collection, analyses, or interpretation of data; in the writing of the manuscript, or in the decision to publish the results.

\section{References}

1. Sofos, J.N. Sorbate Food Preservatives; CRC Press: Boca Raton, FL, USA, 1989; 248p.

2. Liewen, M.B.; Marth, E.H. Growth and Inhibition of Microorganisms in the Presence of Sorbic Acid: A Review. J. Food Prot. 1985, 48, 364-375. [CrossRef] [PubMed]

3. Naidu, A.S. Natural Food Antimicrobial Systems. Nat. Food Antimicrob. Syst. 2000. [CrossRef]

4. Harrison, R. Food Preservatives. Springer Sci. Bus. Media 1906, 168, 4338. [CrossRef]

5. Sofos, J.N.; Pierson, M.D.; Blocher, J.C.; Busta, F.F. Mode of Action of Sorbic Acid on Bacterial Cells and Spores. Int. J. Food Microbiol. 1986, 3, 1-17. [CrossRef]

6. York, G.K.; Vaughn, R.H. Mechanisms in the Inhibition of Microorganisms by Sorbic Acid. J. Bacteriol. 1964, 88, 411-417. [CrossRef]

7. Smoot, L.A.; Pierson, M.D. Mechanisms of Sorbate Inhibition of Bacillus cereus T and Clostridium botulinum 62A Spore Germination. Appl. Environ. Microbiol. 1981, 42, 477-483. [CrossRef]

8. Costilow, R.; Ferguson, W.; Ray, S. Sorbic Acid as a Selective Agent in Cucumber Fermentations. Appl. Microbiol. 1955, 6, 341-345. [CrossRef]

9. Sayeed, S.A.; Sankaran, R. Action of Sorbic Acid on Staphylococcus Metabolism: A Microcalorimetric Investigation. Indian J. Exp. Biol. 1991, 29, 628-630.

10. Kinderlerer, P.V. Fungal Metabolites of Sorbic Acid. Food Addit. Contam. 1990, 7, 657-669. [CrossRef]

11. Lide, D.R.; Baysinger, G. Physical Constants of Organic Compounds. CRC Handb. Chem. Phys. 2019, 313-576. [CrossRef]

12. Hoag, S.W.; Hussain, A.S. The Impact of Formulation on Bioavailability. J. Nutr. 2001, 131, 1389-1391. [CrossRef] [PubMed]

13. Guzman, J.D. Natural Cinnamic Acids, Synthetic Derivatives and Hybrids with Antimicrobial Activity. Molecules 2014, 19, 19292-19349. [CrossRef] [PubMed]

14. Kabara, J.J. Antimicrobial Agents Derived from Fatty Acids. J. Am. Oil Chem. Soc. 1984, 61, 397-403. [CrossRef]

15. Jahangiri, A.; Møller, A.H.; Danielsen, M.; Madsen, B.; Joernsgaard, B.; Vaerbak, S.; Adlercreutz, P.; Dalsgaard, T.K. Hydrophilization of Bixin by Lipase-Catalyzed Transesterification with Sorbitol. Food Chem. 2018, 268, 203-209. [CrossRef] [PubMed]

16. Kumar, A.; Dhar, K.; Kanwar, S.S.; Arora, P.K. Lipase Catalysis in Organic Solvents: Advantages and Applications. Biol. Proced. Online 2016, 18, 1-11. [CrossRef]

17. Ravelo, M.; Fuente, E.; Blanco, Á.; Ladero, M.; García-Ochoa, F. Esterification of Glycerol and Ibuprofen in Solventless Media Catalyzed by Free CALB: Kinetic Modelling. Biochem. Eng. J. 2015, 101, 228-236. [CrossRef] 
18. Radzi, S.M.; Basri, M.; Salleh, A.B.; Ariff, A.; Mohammad, R.; Rahman, M.B.A.; Rahman, R.N.Z.R.A. Large Scale Production of Liquid Wax Ester by Immobilized Lipase. J. Oleo Sci. 2005, 54, 203-209. [CrossRef]

19. Tamayo, J.J.; Ladero, M.; Santos, V.E.; García-Ochoa, F. Esterification of Benzoic Acid and Glycerol to $\alpha$-Monobenzoate Glycerol in Solventless Media Using an Industrial Free Candida antarctica Lipase B. Process Biochem. 2012, 47, 243-250. [CrossRef]

20. Conley, A.J.; Kabara, J.J. Antimicrobial Action of Esters of Polyhydric Alcohols. Antimicrob. Agents Chemother. 1973, 4, 501-506. [CrossRef]

21. Kiran, S.; Kamal, S.; Aslam, N.; Hussain, A.I.; Ghaffar, A.; Bibi, I.; Kamal, A.; Munir, B.; Sultan, N. Synthesis of Ibuprofen Derivatives with Improved Antibacterial Activity. Asian J. Chem. 2015, 27, 3259-3262. [CrossRef]

22. Ghanem, A. Trends in Lipase-Catalyzed Asymmetric Access to Enantiomerically Pure/Enriched Compounds. Tetrahedron 2007, 63, 1721-1754. [CrossRef]

23. Chiaradia, V.; Paroul, N.; Cansian, R.L.; Júnior, C.V.; Detofol, M.R.; Lerin, L.A.; Oliveira, J.V.; Oliveira, D. Synthesis of Eugenol Esters by Lipase-Catalyzed Reaction in Solvent-Free System. Appl. Biochem. Biotechnol. 2012, 168, 742-751. [CrossRef]

24. Giovannini, P.P.; Catani, M.; Massi, A.; Sacchetti, G.; Tacchini, M.; de Oliveira, D.; Lerin, L.A. Continuous Production of Eugenol Esters Using Enzymatic Packed-Bed Microreactors and an Evaluation of the Products as Antifungal Agents. Flavour Fragr. J. 2019, 34, 201-210. [CrossRef]

25. Ortiz, C.; Ferreira, M.L.; Barbosa, O.; Dos Santos, J.C.S.; Rodrigues, R.C.; Berenguer-Murcia, Á.; Briand, L.E.; Fernandez-Lafuente, R. Novozym 435: The "Perfect" Lipase Immobilized Biocatalyst? Catal. Sci. Technol. 2019, 9, 2380-2420. [CrossRef]

26. Foresti, M.L.; Galle, M.; Ferreira, M.L.; Briand, L.E. Enantioselective Esterification of Ibuprofen with Ethanol as Reactant and Solvent Catalyzed by Immobilized Lipase: Experimental Andmolecular Modeling Aspects. J. Chem. Technol. Biotechnol. 2009, 84, 1461-1473. [CrossRef]

27. Trodler, P.; Pleiss, J. Modeling Structure and Flexibility of Candida antarctica Lipase B in Organic Solvents. BMC Struct. Biol. 2008, 8, 1-10. [CrossRef]

28. Ong, A.L.; Kamaruddin, A.H.; Bhatia, S.; Long, W.S.; Lim, S.T.; Kumari, R. Performance of Free Candida antarctica Lipase B in the Enantioselective Esterification of (R)-Ketoprofen. Enzyme Microb. Technol. 2006, 39, 924-929. [CrossRef]

29. Nordblad, M.; Adlercreutz, P. Immobilisation Procedure and Reaction Conditions for Optimal Performance of Candida antarctica Lipase B in Transesterification and Hydrolysis. Biocatal. Biotransform. 2013, 31, 237-245. [CrossRef]

30. Manoel, E.A.; dos Santos, J.C.S.; Freire, D.M.G.; Rueda, N.; Fernandez-Lafuente, R. Immobilization of Lipases on Hydrophobic Supports Involves the Open Form of the Enzyme. Enzyme Microb. Technol. 2015, 71, 53-57. [CrossRef]

31. Pagliaro, M.; Ciriminna, R.; Kimura, H.; Rossi, M.; Della Pina, C. From Glycerol to Value-Added Products. Angew. Chem. Int. Ed. 2007, 46, 4434-4440. [CrossRef]

32. Bradbury, S.L.; Jakoby, W.B. Glycerol as an Enzyme-Stabilizing Agent: Effects on Aldehyde Dehydrogenase. Proc. Natl. Acad. Sci. USA 1972, 69, 2373-2376. [CrossRef] [PubMed]

33. Ohtake, S.; Kita, Y.; Arakawa, T. Interactions of Formulation Excipients with Proteins in Solution and in the Dried State. Adv. Drug Deliv. Rev. 2011, 63, 1053-1073. [CrossRef] [PubMed]

34. Vagenende, V.; Yap, M.G.S.; Trout, B.L. Mechanisms of Protein Stabilization and Prevention of Protein Aggregation by Glycerol. Biochemistry 2009, 48, 11084-11096. [CrossRef] [PubMed]

35. Kumar, V.; Chari, R.; Sharma, V.K.; Kalonia, D.S. Modulation of the Thermodynamic Stability of Proteins by Polyols: Significance of Polyol Hydrophobicity and Impact on the Chemical Potential of Water. Int. J. Pharm. 2011, 413, 19-28. [CrossRef] [PubMed]

36. Wolfson, A.; Atyya, A.; Dlugy, C.; Tavor, D. Glycerol Triacetate as Solvent and Acyl Donor in the Production of Isoamyl Acetate with Candida antarctica Lipase B. Bioprocess Biosyst. Eng. 2010, 33, 363-366. [CrossRef]

37. Wolfson, A.; Dlugy, C.; Shotland, Y. Glycerol as a Green Solvent for High Product Yields and Selectivities. Environ. Chem. Lett. 2007, 5, 62-71. [CrossRef]

38. Ravelo, M.; Wojtusik, M.; Ladero, M.; García-Ochoa, F. Synthesis of Ibuprofen Monoglyceride in Solventless Medium with Novozym®435: Kinetic Analysis. Catalysts 2020, 10, 76. [CrossRef]

39. Katzung, B.G. Basic E Clinical Pharmacology; McGraw-Hill Educ.: New York, NY, USA, 2018. 
40. Zhao, H.; Song, Z. Migration of Reactive Trace Compounds from Novozym®435 into Organic Solvents and Ionic Liquids. Biochem. Eng. J. 2010, 49, 113-118. [CrossRef]

41. Kobayashi, T.; Matsuo, T.; Kimura, Y.; Adachi, S. Thermal Stability of Immobilized Lipase from Candida antarctica in Glycerols with Various Water Contents at Elevated Temperatures. JAOCS, J. Am. Oil Chem. Soc. 2008, 85, 1041-1044. [CrossRef]

42. Foresti, M.L.; Pedernera, M.; Bucalá, V.; Ferreira, M.L. Multiple Effects of Water on Solvent-Free Enzymatic Esterifications. Enzyme Microb. Technol. 2007, 41, 62-70. [CrossRef]

43. Bouaziz, A.; Horchani, H.; Salem, N.B.; Chaari, A.; Chaabouni, M.; Gargouri, Y.; Sayari, A. Enzymatic Propyl Gallate Synthesis in Solvent-Free System: Optimization by Response Surface Methodology. J. Mol. Catal. B Enzym. 2010, 67, 242-250. [CrossRef]

44. van Vuuren, S.F. Antimicrobial Activity of South African Medicinal Plants. J. Ethnopharmacol. 2008, 119, 462-472. [CrossRef] [PubMed]

45. Piper, J.D.; Piper, P.W. Benzoate and Sorbate Salts: A Systematic Review of the Potential Hazards of These Invaluable Preservatives and the Expanding Spectrum of Clinical Uses for Sodium Benzoate. Compr. Rev. Food Sci. Food Saf. 2017, 16, 868-880. [CrossRef]

46. Doležálková, I.; Máčalík, Z.; Butkovičová, A.; Janiš, R.; Buňková, L. Monoacylglycerols as Fruit Juices Preservatives. Czech J. Food Sci. 2012, 30, 567-572. [CrossRef]

47. Chaibi, A.; Ababouch, L.H.; Busta, F.F. Inhibition by Monoglycerides of L-Alanine-Triggered Bacillus cereus and Clostridium botulinum Spore Germination and Outgrowth. J. Food Prot. 1996, 59, 832-837. [CrossRef] [PubMed]

48. Yoon, B.K.; Jackman, J.A.; Valle-González, E.R.; Cho, N.J. Antibacterial Free Fatty Acids and Monoglycerides: Biological Activities, Experimental Testing, and Therapeutic Applications. Int. J. Mol. Sci. 2018, $19,1114$. [CrossRef] [PubMed]

(C) 2020 by the authors. Licensee MDPI, Basel, Switzerland. This article is an open access article distributed under the terms and conditions of the Creative Commons Attribution (CC BY) license (http://creativecommons.org/licenses/by/4.0/). 